\title{
Discrimination between spinal cord injury and cervical compressive myelopathy in intramedullary high-intensity lesions on T2-weighted magnetic resonance imaging
}

Naosuke Kamei ( $\square$ nahkamei@hiroshima-u.ac.jp )

Hiroshima University https://orcid.org/0000-0001-5076-0145

Kazuyoshi Nakanishi

Nihon University

Toshio Nakamae

Hiroshima University

Takayuki Tamaura

Hiroshima University

Yuji Tsuchikawa

Hiroshima University

Taiki Morisako

Hiroshima University

Takahiro Harada

Hiroshima University

Toshiaki Maruyama

Hiroshima University

Nobuo Adachi

Hiroshima University

Research article

Keywords: whiplash, spinal cord injury, myelopathy, MRI, T2

Posted Date: October 13th, 2020

DOl: https://doi.org/10.21203/rs.3.rs-90889/v1

License: (c) (1) This work is licensed under a Creative Commons Attribution 4.0 International License.

Read Full License 


\section{Abstract}

Background: When intramedullary high-intensity lesions are found on cervical T2-weighted magnetic resonance images of patients with whiplash injury, it is often required to identify whether they are due to spinal cord injury (SCI) or cervical compressive myelopathy (CCM). This is important to determine insurance coverage. Thus, this study aimed to develop a method to distinguish between SCl and CCM.

Methods: Magnetic resonance images of 20 patients who had cervical SCI were evaluated. These $20 \mathrm{SCl}$ patients were age- and sex-matched to $20 \mathrm{CCM}$ patients. The number of discs adjacent to T2 highintensity lesions was counted because the T2 high-intensity lesions in $\mathrm{SCl}$ were characterized by sagittal dilation. The "snake-eyes appearance" was assessed as a characteristic finding of CCM. T2 values in T2 high-intensity lesions were evaluated quantitatively by its ratio with the T2 values in the normal spinal cord, including signal ratio and contrast ratio.

Results: The number of discs adjacent to T2 high-intensity lesions was significantly higher in $\mathrm{SCl}$ than in CCM. The snake-eyes appearance was found in 9 of $20 \mathrm{CCM}$ patients, but not in SCl patients. The signal ratio and contrast ratio on axial images were significantly higher in $\mathrm{SCl}$ than in $\mathrm{CCM}$. A new diagnostic scale was created based on these results. This diagnostic scale has made it possible to distinguish $\mathrm{SCl}$ and CCM with $>90 \%$ accuracy from all perspectives including sensitivity, specificity, positive predictive value, and negative predictive value.

Conclusions: The features of T2 high-intensity lesions can be used to distinguish between $\mathrm{SCl}$ and CCM.

\section{Background}

Whiplash injury following a traffic accident is caused by sudden movements of the neck such as extension and flexion. Whiplash injury has major symptoms such as neck tenderness, pain upon movement, and restricted movement and various other symptoms such as headache, dizziness, weakness, tinnitus, and visual impairment. The collection of these symptoms is called whiplashassociated disorder (WAD) [1-3]. WAD often becomes chronic, requiring high financial costs [4-6]. Several studies have suggested the presence of mild spinal cord injury (SCI) in WAD [7-9]. The presence of SCl is important in determining the amount of insurance compensation for whiplash injury.

Intramedullary high-intensity lesion in the cervical spinal cord detected by T2-weighted magnetic resonance imaging (MRI) is one of the possible signs of $\mathrm{SCl}$ [10]. However, intramedullary T2 highintensity lesion is also observed in patients with cervical compressive myelopathy (CCM) [11]. With the aging of the population, the number of patients with $\mathrm{SCl}$ without bone injury and $\mathrm{CCM}$ is increasing [1214]. Therefore, it is often necessary to determine whether the cause of intramedullary T2 high-intensity lesion in a whiplash patient is $\mathrm{SCl}$ or $\mathrm{CCM}$. Although physicians familiar with spine surgery use empirical knowledge to distinguish between $\mathrm{SCl}$ and $\mathrm{CCM}$, there is no clear identification method. 
Thus, in this study, we aimed to develop a method to distinguish between $\mathrm{SCl}$ and $\mathrm{CCM}$ by quantifying the features of intramedullary T2 high-intensity lesions in the cervical spinal cord.

\section{Methods}

This study was approved by our institutional review board.

\section{MRI assessments}

In this study, 1.5 tesla $(T)$ or 3.0-T MR scanners were used. MR images of 20 patients who had cervical spinal cord injury without bone injury or dislocation and transferred to our hospital between 2015 and 2019 (SCl group) were evaluated. A bone bruise that could be judged only by MRI was not judged as a bone injury. MR images were taken in 13 patients on the day of injury, in four patients the day after the injury, and three patients 2 days after the injury. For comparison, we also evaluated the MR images of 20 patients with a clear diagnosis of CCM in our clinic in 2019. Patients with intramedullary T2 high-intensity lesions in the cervical spinal cord who matched in age and sex with the patients in the SCl group were selected (CCM group). The sagittal or axial T2-weighted images were used for evaluation. The slice with the largest T2 high-intensity lesion was selected for both sagittal and axial images.

Signal intensity (SI) values were acquired by defining the region of interest (ROI) at the T2 high-intensity lesion and in the spinal cord at the first thoracic vertebral body level on sagittal (Fig.1a, d, circles) and axial (Fig. 1b-f, circles) images. The ROls of over 50 pixels were taken for each point because of the decreased bias of the image. Additionally, sagittal extent and snake-eyes appearance (SEA) were assessed as features of T2 high-intensity lesions. The sagittal extent of T2 high-intensity lesions was assessed by the number of intervertebral discs adjacent to the consistent lesion (Fig.1a, d, arrows). The SEA was characterized as a symmetrical bilateral small high-intensity lesion on an axial T2-weighted MRI [15] (Fig. 1e). Spinal surgeons with $>15$ years of experience (KN and TN) performed the MRI evaluations for each patient. The observers were blinded to the patients' data. The average SI values of the two observers were used in this study.

\section{Signal ratio and contrast ratio on MRI}

The SI values of the T2 high-intensity lesion $(\mathrm{H})$ and the spinal cord $(\mathrm{C})$ were used to calculate the signal ratio (SR) and contrast ratio (CR). The SR and CR were calculated according to the following formulae $[16,17]$ :

$\mathrm{SR}=\mathrm{H} / \mathrm{C}$

$\mathrm{CR}=(\mathrm{H}-\mathrm{C}) /(\mathrm{H}+\mathrm{C})$

\section{Statistical analysis}


Data were expressed as mean values \pm standard deviation. Data were analyzed using the JMP ${ }^{\circledR} 15$ (SAS Institute Inc., Cary, NC). Mann-Whitney $U$ test was used to compare the the two groups. One-way analysis of variance (ANOVA), followed by Tukey's post-hoc test, was performed for multiple comparisons. $\mathrm{P}<$ 0.05 was considered to denote statistical significance.

\section{Diagnostic scale}

Our original diagnostic scale was devised considering the difference between SCl and CCM in the features of intramedullary T2 high-intensity lesions including the sagittal range of T2 high-intensity lesions, presence of SEA, and CR (Table 1). Each patient was scored and evaluated using our new diagnostic scale.

Table 1. Diagnostic scale

\begin{tabular}{|c|c|c|}
\hline \multicolumn{2}{|c|}{} & Score \\
\hline Number of Discs & 1 & $\mathbf{1}$ \\
\cline { 2 - 3 } & 2 & $\mathbf{2}$ \\
\cline { 2 - 3 } & $\geq 3$ & $\mathbf{3}$ \\
\hline Contrast Ratio & $>0.17$ & $\mathbf{2}$ \\
\cline { 2 - 3 } & $0.17-0.12$ & $\mathbf{1}$ \\
\cline { 2 - 3 } & $<0.12$ & $\mathbf{0}$ \\
\hline SEA + & & $\mathbf{- 3}$ \\
\hline
\end{tabular}

\section{Results}

\section{Demographic data}

The SCl group was composed of 20 patients (17 men and three women) with a mean age of 65.2 (range, 22-82) years. The degree of spinal cord injury was Frankel $A$ in one, Frankel $B$ in one, Frankel $C$ in 13 , and Frankel $D$ in five patients. The CCM group was also composed of 20 age- and sex-matched patients (17 men and three women), with a mean age of 64.1 (range, 36-82) years. T2 high-intensity lesions were located from C2-3 to C5-6.

\section{Sagittal extent of the T2 high-intensity lesions}

On MRI, the intramedullary T2 high-intensity lesions of SCl often spread vertically, and CCM lesions were mainly localized between vertebrae (Fig. 1). The number of intervertebral discs adjacent to the T2 highintensity lesion in sagittal MR images was $1.95 \pm 0.99$ in the SCl group and $1.25 \pm 0.44$ in the CCM group 
(Fig. 2). The number of intervertebral discs in the SCl group was significantly greater than that in the CCM group $(p=0.017)$.

\section{SEA}

In axial MR images, T2 high-intensity lesions in SCl often spread from the gray matter to the white matter with unclear borders, but in CCM, they had clear borders and were localized to the gray matter (Fig. 1). However, these features could only be evaluated subjectively. Therefore, the presence of SEA was used as an objective feature of CCM. Although the presence of SEA in axial MR images was observed in nine CCM patients, it never existed in SCl patients (Table 2).

Table 2. Presence of snake eyes appearance (SEA)

\begin{tabular}{|c|c|c|}
\hline & SEA + & SEA - \\
\hline SCI & 0 & 20 \\
\hline CCM & 9 & 11 \\
& & \\
\hline
\end{tabular}

\section{Signal ratio and contrast ratio of T2 values}

$T 2$ values on MR images of intramedullary T2 high-intensity lesions were quantified by SR and CR. The average $S R$ values were $1.39 \pm 0.21$ and $1.29 \pm 0.13$ in the sagittal images and $1.43 \pm 0.24$ and $1.26 \pm$ 0.12 in the axial images of the SCl group and CCM group, respectively (Fig. 3a). Comparison results of the $\mathrm{SR}$ values between the $\mathrm{SCl}$ group and the CCM group showed no significant difference in the sagittal view, but a significant difference was noted in the axial view $(p=0.314$ in SCl sagittal vs CSM sagittal, $p=$ 0.021 in SCl axial vs CSM axial). In both SCI and CCM, no significant difference was found between SR values in the sagittal view and in the axial view ( $p=0.894$ in SCl sagittal vs SCl axial, $p=0.955$ in CSM sagittal vs CSM axial). In addition, the average CR values were $0.16 \pm 0.07$ and $0.12 \pm 0.05$ in the sagittal images and $0.17 \pm 0.07$ and $0.11 \pm 0.04$ in the axial images of the SCl group and CCM group, respectively (Fig. $3 b$ ). Comparison results of the $\mathrm{CR}$ values between the $\mathrm{SCl}$ group and the CCM group showed no significant difference in the sagittal view, but a significant difference was observed in the axial view ( $p=$ 0.308 in SCl sagittal vs CSM sagittal, $p=0.017$ in SCl axial vs CSM axial). In both SCI and CCM, no significant difference was noted between $\mathrm{CR}$ values in the sagittal view and in the axial view $(p=0.900$ in $\mathrm{SCl}$ sagittal vs $\mathrm{SCl}$ axial, $p=0.930$ in CSM sagittal vs CSM axial). In the $\mathrm{SCl}$ group, no significant difference was found in the SR or CR values due to the different timing of MRI assessment (Table 3a). However, the SR and CR values in a patient with Frankel A were higher than those in other cases (Table 3b).

Table 3. 
Comparison of SR and CR in SCI by (a) timing of taking MRI and (b) Frankel grade.

a.

\begin{tabular}{|c|c|c|c|}
\hline Days after SCI & 0day $(\mathbf{n = 1 3})$ & 1day $(\mathbf{n}=\mathbf{4})$ & 2days $(\mathbf{n}=\mathbf{3})$ \\
\hline \hline Sagittal-SR & $1.42 \pm 0.23$ & $1.32 \pm 0.21$ & $1.37 \pm 0.12$ \\
\hline Sagittal-CR & $0.17 \pm 0.07$ & $0.13 \pm 0.08$ & $0.16 \pm 0.04$ \\
\hline Axial-SR & $1.48 \pm 0.27$ & $1.36 \pm 0.18$ & $1.33 \pm 0.12$ \\
\hline Axial-CR & $0.18 \pm 0.08$ & $0.15 \pm 0.07$ & $0.14 \pm 0.04$ \\
\hline
\end{tabular}

b.

\begin{tabular}{|c|c|c|c|c|}
\hline Frankel grade & $\mathbf{A}(\mathbf{n}=\mathbf{1})$ & $\mathbf{B}(\mathbf{n}=\mathbf{1})$ & $\mathbf{C}(\mathbf{n}=\mathbf{1 3})$ & $\mathbf{D}(\mathbf{n}=\mathbf{5})$ \\
\hline \hline Sagittal-SR & 1.74 & 1.41 & $1.38 \pm 0.23$ & $1.48 \pm 0.12$ \\
\hline Sagittal-CR & 0.27 & 0.17 & $0.15 \pm 0.08$ & $0.15 \pm 0.04$ \\
\hline Axial-SR & 2.24 & 1.3 & $1.34 \pm 0.13$ & $1.53 \pm 0.15$ \\
\hline Axial-CR & 0.38 & 0.13 & $0.14 \pm 0.05$ & $0.21 \pm 0.05$ \\
\hline
\end{tabular}

\section{Diagnostics using the new scale}

A new diagnostic scale was devised considering the difference in the features in T2 high-intensity lesions between SCl and CCM (Table 1). Because the number of discs adjacent to the T2 high-intensity lesion was significantly higher in $\mathrm{SCl}$ than in $\mathrm{CCM}$, points were assigned to patients with a high number of discs involved and thus were likely diagnosed with $\mathrm{SCl}$. In addition, given the finding that the $\mathrm{CR}$ value in the axial view was significantly higher in SCI than in CCM, patients with larger CR values were assigned points and thus were likely to be diagnosed with $\mathrm{SCl}$. The average CR values in the $\mathrm{SCl}$ and CCM groups were used to determine the boundaries between points. Since SEA was only observed in the CCM group, points were assigned to patients with SEA and likely diagnosed with CCM. The 18 patients in the SCI group and one patient in the CCM group scored $\geq 3$ on this diagnostic scale, while two patients in the SCI group and 19 patients in the CCM group scored $\leq 2$ (Table 4). When patients with a score $\geq 3$ were diagnosed with SCl, the sensitivity, specificity, positive predictive value, and negative predictive value were $90.0 \%, 95.0 \%, 94.7 \%$, and $90.5 \%$, respectively.

Table 4. Diagnostic scores 


\begin{tabular}{|c|c|c|}
\hline \multirow{2}{*}{} & \multicolumn{2}{|l|}{ Diagnostic Score } \\
\cline { 2 - 3 } & $\geq 3$ & $\leq 2$ \\
\hline SCI & $\mathbf{1 8}$ & $\mathbf{2}$ \\
\hline CCM & $\mathbf{1}$ & $\mathbf{1 9}$ \\
\hline
\end{tabular}

\section{Discussion}

This study demonstrated a difference in MRI features of intramedullary T2 high-intensity lesions in the cervical spinal cord between SCI and CCM patients. Specifically, for diagnosis, the T2 values of the lesions were quantified by its ratio with the T2 values of the normal spinal cord. To the best of our knowledge, this is the first study to distinguish $\mathrm{SCl}$ from CCM based on MRI findings.

With the spread of MRI, WAD patients with relatively severe symptoms are becoming more commonly evaluated by MRI of the cervical spine early after injury. If there is compression of the spinal cord due to cervical spinal canal stenosis, the spinal cord can be damaged by whiplash injury without a fracture or dislocation of the cervical spine $[13,18]$. When intramedullary T2 high-intensity lesions in the cervical spinal cord are observed on MRI, it is necessary to distinguish whether SCl or CCM is the cause, because the presence of $\mathrm{SCl}$ is very important in determining insurance coverage. The existing diagnostic method has been based on the empirical knowledge of specialists, because there were no clear diagnostic criteria.

In this study, some features of intramedullary T2 high-intensity lesions were assessed to establish the diagnostic criteria by distinguishing between $\mathrm{SCl}$ and $\mathrm{CCM}$. SCl and $\mathrm{CCM}$ have different pathologies in the intramedullary $\mathrm{T} 2$ high-intensity lesions. In SCl, trauma causes primary injury, followed by secondary injury, including bleeding, ischemia, edema, inflammatory cell infiltration, and neuronal and glial cell death [19]. Intramedullary T2 high-intensity lesions in acute and subacute SCI were reported to primarily reflect edema or hemorrhage $[20,21]$. In a previous study, MR images of acute and subacute SCI showed that T2 high-intensity lesions with unclear boundary spread in the sagittal direction [20]. In the present study, similar features of T2 high-intensity lesion in $\mathrm{SCl}$ were observed. On the contrary, intramedullary T2 high-intensity lesions with sharp boundaries were often confined to the interbody region in CCM. Previous studies also showed this feature [11, 22, 23]. In the present study, the sagittal extent of intramedullary T2 high-intensity lesions was evaluated by the number of adjacent discs. This evaluation showed that the sagittal spread of intramedullary T2 high-intensity lesions was significantly greater in SCI than in CCM. In addition, SEA was previously reported as a characteristic MRI finding of CCM [15, 23]. Moreover, it is the most objectively recognizable feature of CCM in the present study. A previous autopsy study demonstrated that SEA reflected cystic necrosis in the gray matter of the spinal cord [15]. In the present 
study, quantitative assessment of T2 values using SR and CR showed a significant difference between $\mathrm{SCl}$ and CSM on axial images. Moreover, no significant differences in SR and CR values were found between sagittal and axial views. Therefore, it is unclear why significant differences in SR and CR values between $\mathrm{SCl}$ and $\mathrm{CCM}$ were found in the axial view but not in the sagittal view. ROI settings might be more suitable for axial views than for sagittal views. Even in the axial views, no clear difference was sufficient to distinguish between SCI and CSM based on SR or CR values alone. Therefore, in this study, an algorithm was devised to distinguish between $\mathrm{SCl}$ and $\mathrm{CCM}$ by combining the number of discs adjacent to T2 high-intensity lesions, presence of SEA, and CR values in axial images. In addition, a diagnostic scale was created to further simplify the diagnostic algorithm. Diagnosis using this scale made it possible to distinguish $\mathrm{SCl}$ and $\mathrm{CCM}$ with $\geq 90 \%$ accuracy from various viewpoints such as sensitivity, specificity, positive predictive value, and negative predictive value.

Nevertheless, this study had some limitations. The number of cases was small to prove that the diagnostic accuracy using our diagnostic scale is definitely high. Additionally, severe SCI patients were included in the $\mathrm{SCl}$ group. However, patients with mild SCI may be better suited to this study. CCM patients were not consecutive because they were selected to match the age and sex of the SCI patients. Further comparative study with a large number of consecutive patients, including mainly mild SCI patients, is needed. Depending on the observer, there might have been some variations in ROI values. To reduce the image bias in this study, ROls $>50$ pixels were taken at each point, and radiological examinations were performed twice on each patient by two senior spine surgeons.

\section{Conclusions}

This study proposed a new diagnostic method to distinguish between $\mathrm{SCl}$ and CCM based on the features of intramedullary T2 high-intensity lesions on MRI. Our diagnostic scale uses the number of adjacent discs, presence of SEA, and CR of T2 values.

\section{Abbreviations}

WAD: Whiplash-associated disorder

SCl: Spinal cord injury

MRI: Magnetic resonance imaging

CCM: Cervical compressive myelopathy

T: Tesla

SI: Signal intensity

ROI: Region of interest 
SEA: Snake-eyes appearance

SR: Signal ratio

CR: Contrast ratio

ANOVA: Analysis of variance

\section{Declarations}

\section{Ethics approval and consent to participate}

This retrospective study was approved by the institutional review board of Hiroshima University Hospital. Informed consent was waived due to the retrospective analysis of anonymized data.

\section{Consent for publication}

Not applicable.

\section{Availability of data and materials}

The datasets used and analyzed during the current study available from the corresponding author on reasonable request.

\section{Competing interests}

The authors have no competing interest to declare.

\section{Funding}

No external funding received to conduct this study.

\section{Authors' contributions}

NK Interpreted the data, Wrote the literature, KN Analyzed the data, Reviewed the literature, TN Analyzed the data, Reviewed the literature, TT Analyzed the data, Reviewed the literature, YT Collected the data, Reviewed the literature, TM Collected the data, Reviewed the literature, TH Collected the data, Reviewed the literature, TM Collected the data, Reviewed the literature, NA Reviewed the literature

\section{Acknowledgements}

Not Applicable.

\section{Authors' information}


Department of Orthopaedic Surgery, Graduate School of Biomedical and Health Sciences, Hiroshima University, 1-2-3 Kasumi, Minami-ku, Hiroshima, 734-8551, Japan

Naosuke Kamei, Toshio Nakamae, Yuji Tsuchikawa, Taiki Morisako, Takahiro Harada, Toshiaki Maruyama, Nobuo Adachi

Department of Orthopaedic Surgery, Nihon University, 30-1 Oyaguchikamicho, Itabashi-ku, Tokyo, Japan

Kazuyoshi Nakanishi

Department of Clinical Support, Hiroshima University Hospital, 1-2-3 Kasumi, Minami-ku, Hiroshima, 7348551, Japan

Takayuki Tamura

\section{Availability of data and materials}

The datasets used and analyzed during the current study available from the corresponding author on reasonable request.

\section{References}

1. Spitzer WO, Skovron ML, Salmi LR, Cassidy JD, Duranceau J, Suissa S, Zeiss E. Scientific monograph of the Quebec Task Force on Whiplash-Associated Disorders: redefining "whiplash" and its management. Spine (Phila Pa 1976). 1995; 20:1S-73S

2. Tanaka N, Atesok K, Nakanishi K, Kamei N, Nakamae T, Kotaka S, Adachi N. Pathology and Treatment of Traumatic Cervical Spine Syndrome: Whiplash Injury. Adv Orthop. 2018; 2018:4765050.

3. Pastakia K, Kumar S. Acute whiplash associated disorders (WAD). Open Access Emerg Med. 2011; 3:29-32.

4. Carroll LJ, Hogg-Johnson S, Cote P, van der Velde G, Holm LW, Carragee EJ, Hurwitz EL, Peloso PM, Cassidy JD, Guzman J, Nordin M, Haldeman S, Bone, Joint Decade - Task Force on Neck P, Its Associated D. Course and prognostic factors for neck pain in workers: results of the Bone and Joint Decade 2000-2010 Task Force on Neck Pain and Its Associated Disorders. Spine (Phila Pa 1976). 2008; 33:S93-100.

5. Rydman E, Ponzer S, Brisson R, Ottosson C, Pettersson-Jarnbert H. Long-term follow-up of whiplash injuries reported to insurance companies: a cohort study on patient-reported outcomes and impact of financial compensation. Eur Spine J. 2018; 27:1255-1261.

6. Ricciardi L, Stifano V, D'Arrigo S, Polli FM, Olivi A, Sturiale CL. The role of non-rigid cervical collar in pain relief and functional restoration after whiplash injury: a systematic review and a pooled analysis of randomized controlled trials. Eur Spine J. 2019; 28:1821-1828. 
7. Elliott JM, Pedler AR, Cowin G, Sterling M, McMahon K. Spinal cord metabolism and muscle water diffusion in whiplash. Spinal Cord. 2012; 50:474-476.

8. Elliott JM, Dewald JP, Hornby TG, Walton DM, Parrish TB. Mechanisms underlying chronic whiplash: contributions from an incomplete spinal cord injury? Pain Med. 2012; 15:1938-1944

9. Smith AC, Parrish TB, Hoggarth MA, McPherson JG, Tysseling VM, Wasielewski M, Kim HE, Hornby TG, Elliott JM. Potential associations between chronic whiplash and incomplete spinal cord injury. Spinal Cord Ser Cases. 2015; 1:15024.

10. Song J, Mizuno J, Inoue T, Nakagawa H. Clinical evaluation of traumatic central cord syndrome: emphasis on clinical significance of prevertebral hyperintensity, cord compression, and intramedullary high-signal intensity on magnetic resonance imaging. Surg Neurol. 2006; 65:117-123.

11. Al-Mefty O, Harkey LH, Middleton TH, Smith RR, Fox JL. Myelopathic cervical spondylotic lesions demonstrated by magnetic resonance imaging. J Neurosurg. 1988; 68:217-222.

12. Montgomery DM, Brower RS. Cervical spondylotic myelopathy. Clinical syndrome and natural history. Orthop Clin North Am. 1992; 23:487-493.

13. Tetreault L, Goldstein CL, Arnold P, Harrop J, Hilibrand A, Nouri A, Fehlings MG. Degenerative Cervical Myelopathy: A Spectrum of Related Disorders Affecting the Aging Spine. Neurosurgery. 2015; 77 Suppl 4:S51-67.

14. Badhiwala JH, Ahuja CS, Akbar MA, Witiw CD, Nassiri F, Furlan JC, Curt A, Wilson JR, Fehlings MG. Degenerative cervical myelopathy - update and future directions. Nat Rev Neurol. 2020; 16:108-124.

15. Mizuno J, Nakagawa H, Inoue T, Hashizume Y. Clinicopathological study of "snake-eye appearance" in compressive myelopathy of the cervical spinal cord. J Neurosurg. 2003; 99:162-168.

16. Downs RK, Bashir MH, Ng CK, Heidenreich JO. Quantitative contrast ratio comparison between T1 (TSE at 1.5T, FLAIR at 3T), magnetization prepared rapid gradient echo and subtraction imaging at 1.5T and 3T. Quant Imaging Med Surg. 2013; 3:141-146.

17. Goode AR, Snyder C, Snyder A, Collins P, DeLorenzo M, Lin PJ. Signal and contrast to noise ratio evaluation of fluoroscopic loops for interventional fluoroscope quality control. J Appl Clin Med Phys. $2019 ; 20: 172-180$.

18. New PW, Cripps RA, Bonne Lee B. Global maps of non-traumatic spinal cord injury epidemiology: towards a living data repository. Spinal Cord. 2014; 52:97-109.

19. Oyinbo CA. Secondary injury mechanisms in traumatic spinal cord injury: a nugget of this multiply cascade. Acta Neurobiol Exp (Wars). 2011; 71:281-299

20. Chandra J, Sheerin F, Lopez de Heredia L, Meagher T, King D, Belci M, Hughes RJ. MRI in acute and subacute post-traumatic spinal cord injury: pictorial review. Spinal Cord. 2012; 50:2-7.

21. Tarawneh AM, D'Aquino D, Hilis A, Eisa A, Quraishi NA. Can MRI findings predict the outcome of cervical spinal cord Injury? a systematic review. Eur Spine J. 2020; 29:2457-64.

22. Matsuda Y, Miyazaki K, Tada K, Yasuda A, Nakayama T, Murakami H, Matsuo M. Increased MR signal intensity due to cervical myelopathy. Analysis of 29 surgical cases. J Neurosurg. 1991; 
74:887-892.

23. Vedantam A, Rajshekhar V. Does the type of T2-weighted hyperintensity influence surgical outcome in patients with cervical spondylotic myelopathy? A review. Eur Spine J. 2013; 22:96-106.

Figures

\section{$\mathrm{SCl}$}
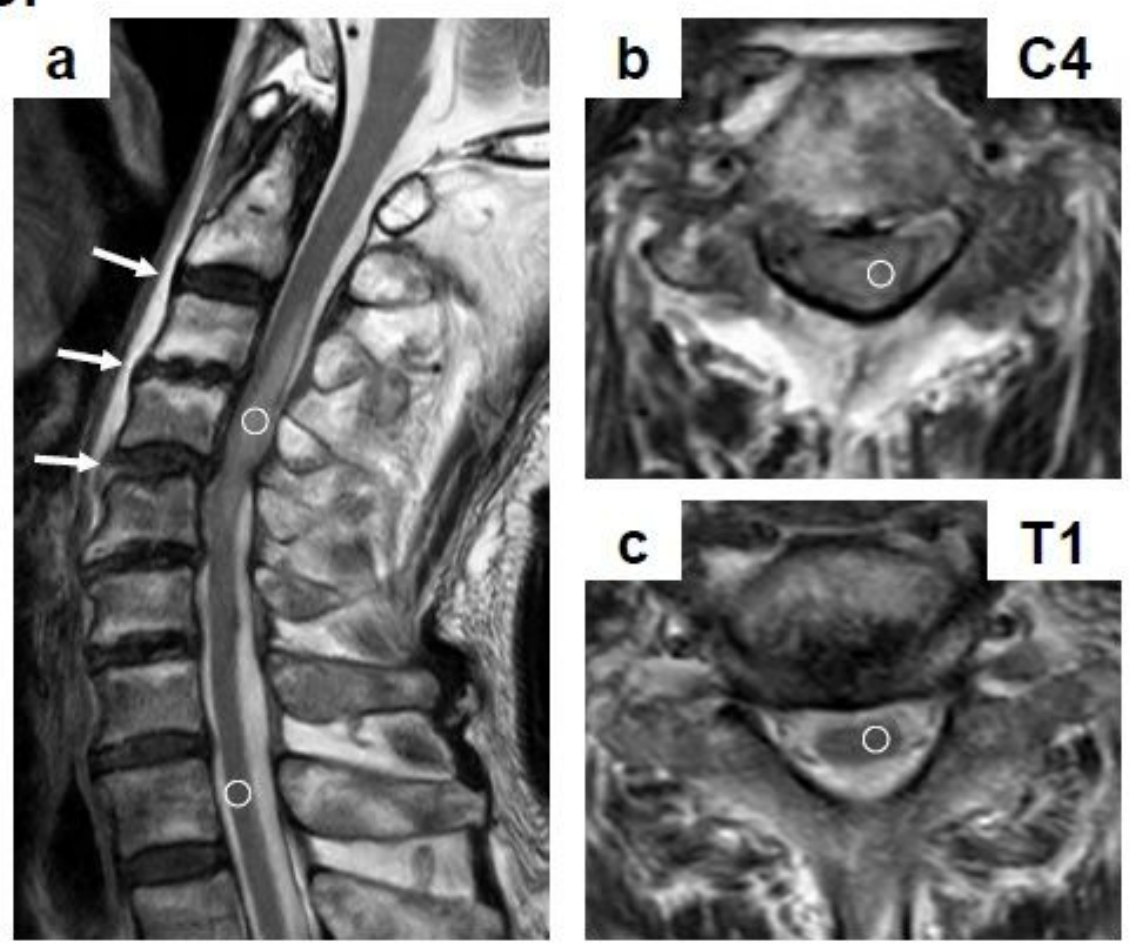

CCM
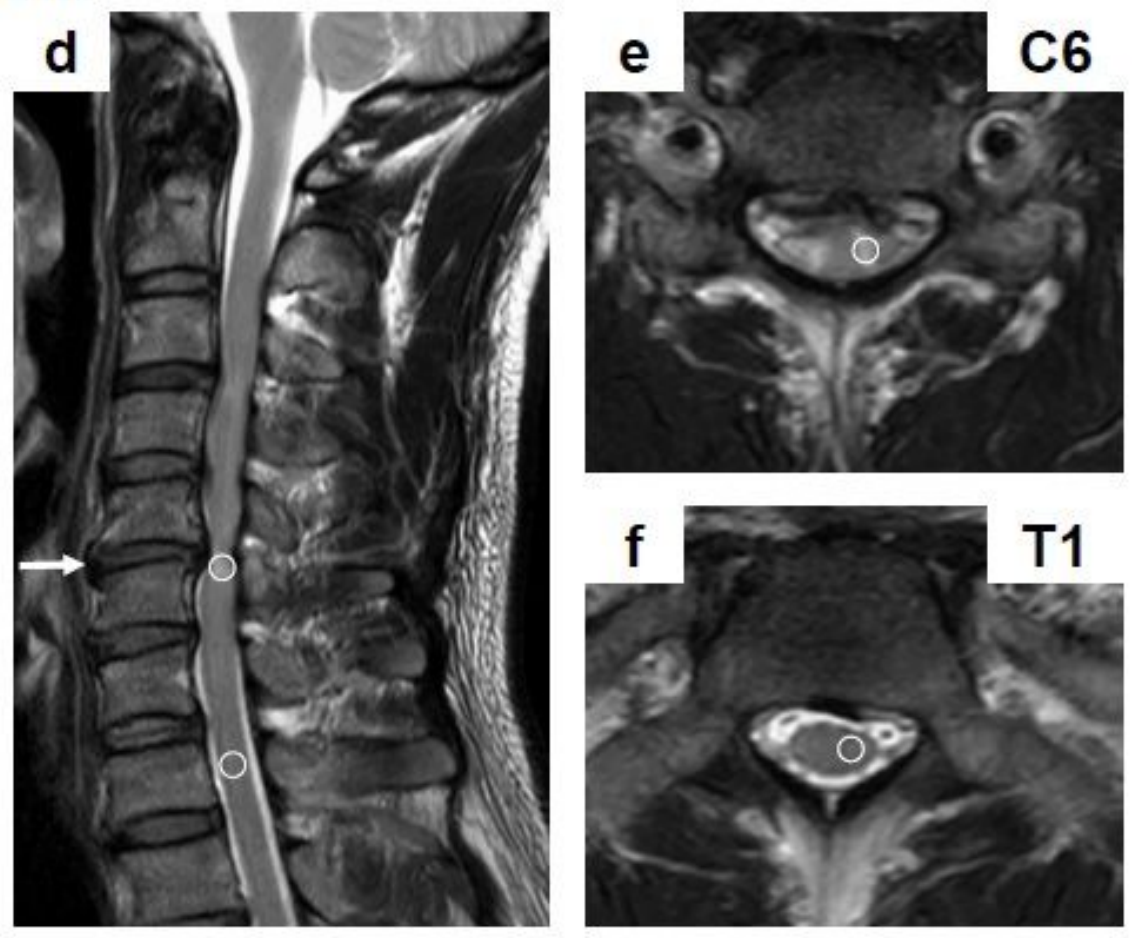
Figure 1

Area where the T2 signal intensities were measured in the SCI group (a-c) and the CCM group (d-f). The white circles on the sagittal and axial T2-weighted images indicate regions of interest (ROI) in the intramedullary T2 high-intensity lesions $(a, b, d, e)$ and in similar parts of the spinal cord at the T1 level (a, $c, d, f)$. CCM, cervical compressive myelopathy; $\mathrm{SCl}$, spinal cord injury

\section{Number of intervertebral discs}

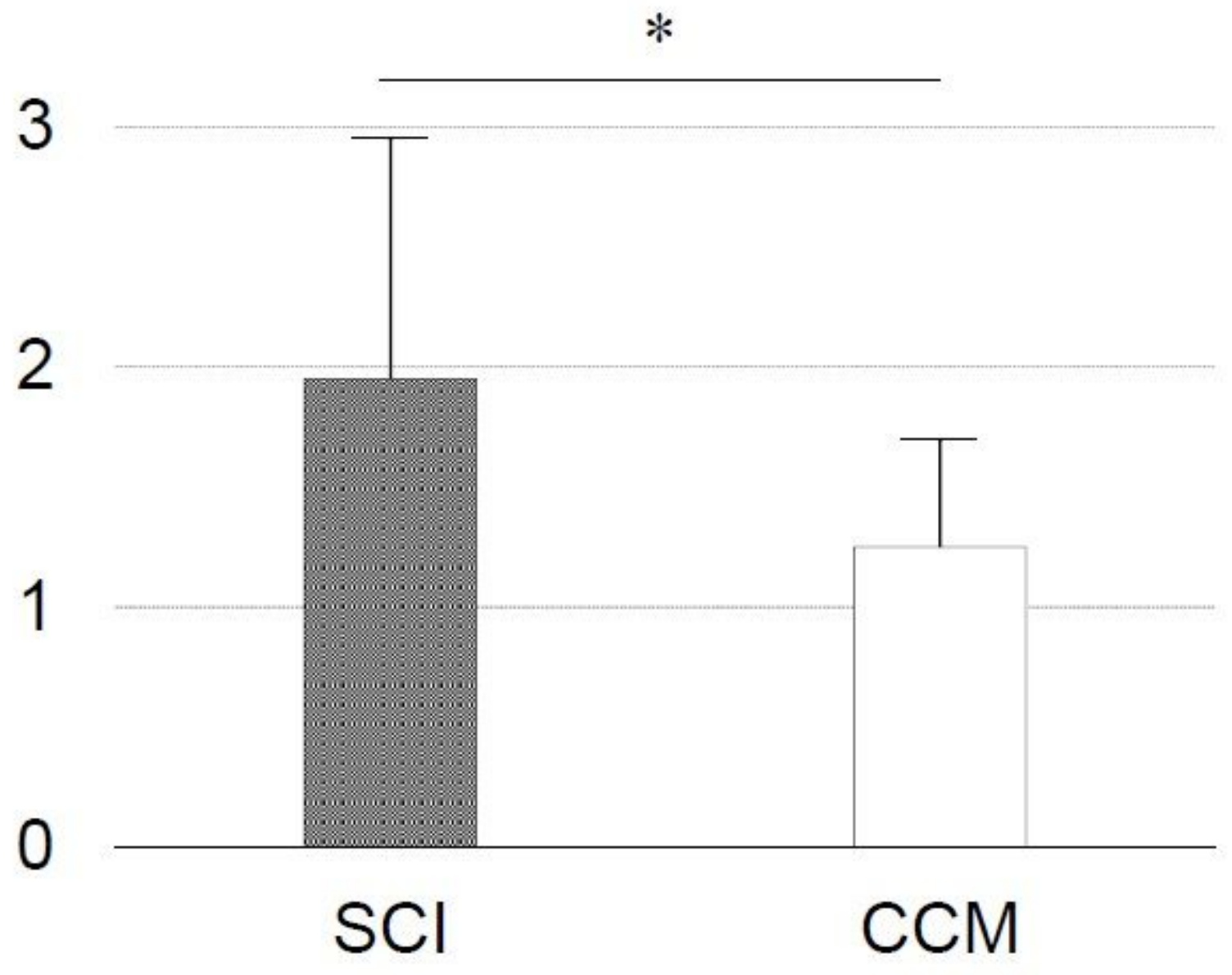

Figure 2

The number of intervertebral discs adjacent to intramedullary T2 high-intensity lesions. The number of discs in the $\mathrm{SCl}$ group was significantly greater than that in the CCM group. * Significant difference, $\mathrm{p}<$ 0.05 (Mann-Whitney U test). CCM, cervical compressive myelopathy; SCl, spinal cord injury 
a

\section{Signal Ratio}

圆 $\mathrm{SCl} \square \mathrm{CCM}$

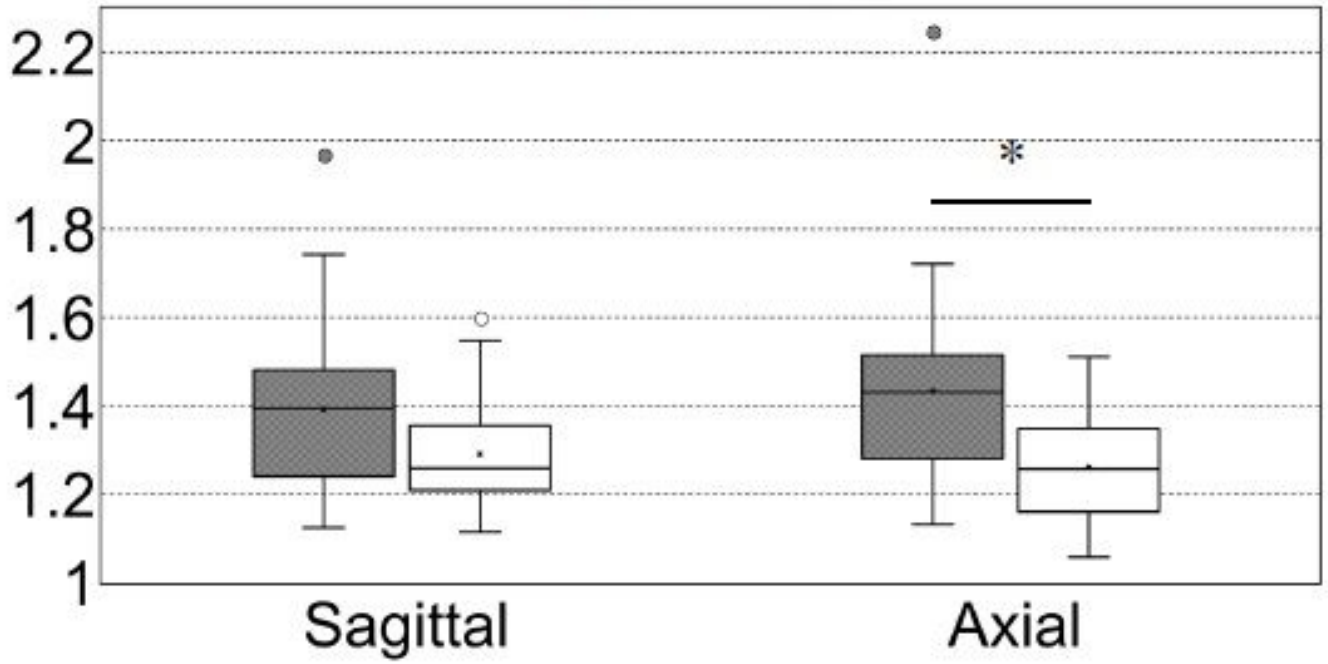

b

Contrast Ratio

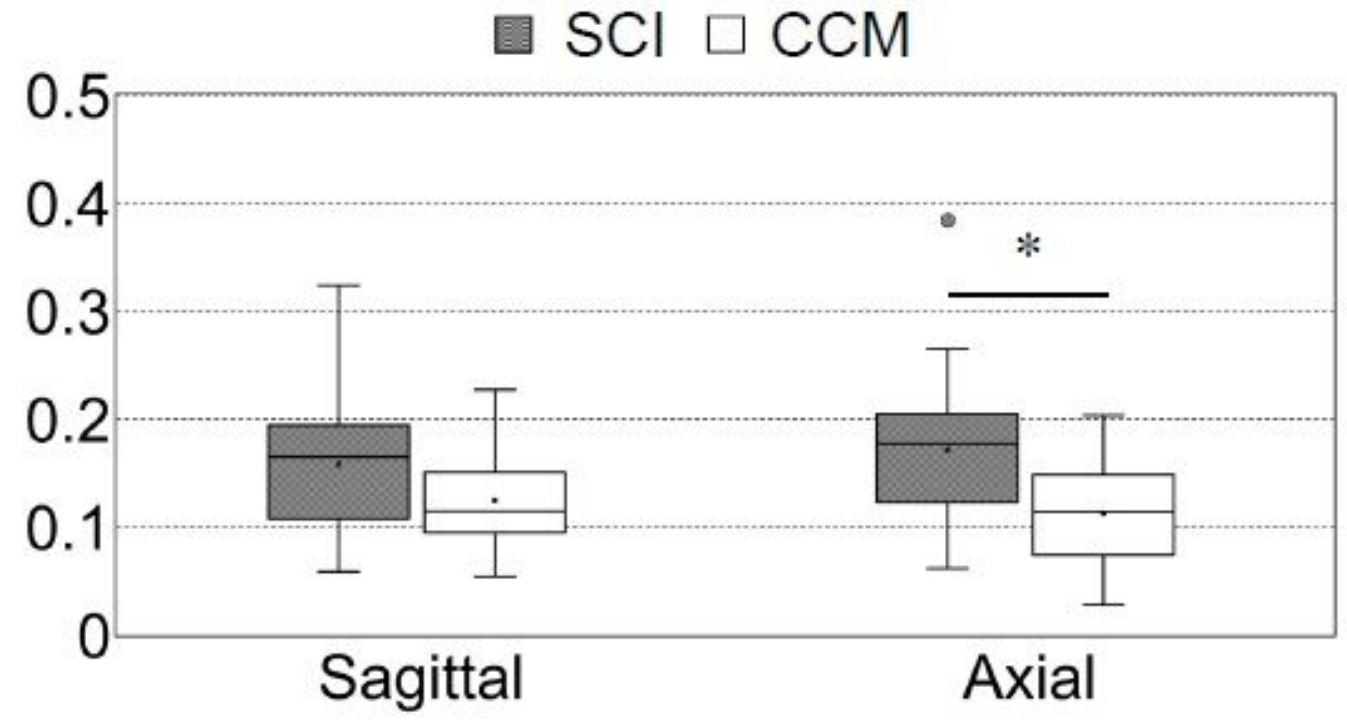

Figure 3

Box plot of the signal ratio (a) and contrast ratio (b) calculated from T2 values of intramedullary T2 highintensity lesions and the spinal cord at T1 levels on sagittal and axial images. The signal and contrast ratios of the SCI group in the axial image were significantly higher than those of the CCM group. * Significant difference, $p<0.05$ (one-way analysis of variance with Tukey's post-hoc test). CCM, cervical compressive myelopathy; $\mathrm{SCl}$, spinal cord injury 